\title{
Fetal cardiovascular remodelling persists at 6 months of life in infants with intrauterine growth restriction
}

Mónica Cruz-Lemini ${ }^{1}$; Fátima Crispi $^{1}$; Brenda Valenzuela-Alcaraz ${ }^{1}$; Francesc Figueras ${ }^{1}$; Marta Sitges $^{2}$; Bart Bijnens ${ }^{3}$; Eduard Gratacós ${ }^{1}$

${ }^{1}$ BCNatal - Barcelona Center for Maternal-Fetal and Neonatal Medicine (Hospital Clínic and Hospital Sant Joan de Deu), Institut d'Investigacions Biomèdiques August Pi i Sunyer, Universitat de Barcelona, and Centre for Biomedical Research on Rare Diseases (CIBER-ER), Barcelona, Spain.

${ }^{2}$ Department of Cardiology (Institut Clínic del Tòrax), Hospital Clínic - Institut d'Investigacions Biomèdiques August Pi i Sunyer, Universitat de Barcelona, Barcelona, Spain.

${ }^{3}$ ICREA - Universitat Pompeu Fabra, Barcelona, Spain.

Address for correspondence: Eduard Gratacós, Head \& Professor, Department of MaternalFetal Medicine, BCNatal - Barcelona Center for Maternal-Fetal and Neonatal Medicine (Hospital Clínic and Hospital Sant Joan de Deu). Sabino de Arana 1, 08028 Barcelona, Spain. Telephone: +34 93227 9931; Fax: +34 93227 5612. E-mail: gratacos@clinic.ub.es

This article has been accepted for publication and undergone full peer review but has not been through the copyediting, typesetting, pagination and proofreading process, which may lead to differences between this version and the Version of Record. Please cite this article as doi: $10.1002 /$ uog. 15767

This article is protected by copyright. All rights reserved. 


\section{ABSTRACT}

Objectives: Intrauterine growth restriction (IUGR) is associated with increased cardiovascular risk later in life but the link between fetal disease and postnatal risk is poorly documented. We evaluated longitudinally the association between cardiovascular remodelling in fetal life and at 6 months of age in IUGR.

Methods: A cohort of 80 IUGR (estimated fetal and birth weight $<10$ th centile, delivery $>34$ weeks' gestation) was compared with 80 normally grown control fetuses, and followed at 6 months of corrected age. Cardiovascular evaluation included a comprehensive echocardiographic assessment (fetuses and infants), and blood pressure and aortic intimamedia thickness (aIMT) in infants. Parameters were adjusted by gender, gestational age at delivery, prenatal glucocorticoid exposure, cesarean section, neonatal intensive care and body surface area by linear regression analysis.

Results: When compared to controls, IUGR showed more globular cardiac shape both preand postnatally (infant left sphericity index: control 1.92 vs. IUGR $1.67, \mathrm{p}-<0.001$ ), as well as signs of systolic longitudinal dysfunction (infant mitral lateral annular S' peak velocity: control 7.9 vs. IUGR $6.4 \mathrm{~cm} / \mathrm{s}, \mathrm{p}-<0.001$; tricuspid annular plane systolic excursion: control 16.0 vs. IUGR $14.2 \mathrm{~mm}, \mathrm{p}-<0.001$ ) and diastolic dysfunction (isovolumetric relaxation time: control 50 vs. IUGR $57 \mathrm{~ms}, \mathrm{p}-<0.001)$. In addition, IUGR infants had increased mean blood pressure (mean: control 61 vs. IUGR $70 \mathrm{mmHg}, \mathrm{p}-<0.001$ ) and maximum aIMT (control 0.57 vs. IUGR $0.66 \mathrm{~mm}, \mathrm{p}-<0.001)$.

Conclusions: Primary cardiovascular changes in IUGR are already present in utero and persist at 6 months of age. The data supports prenatal cardiovascular remodelling as a mechanistic pathway of increased risk in IUGR.

Keywords: Cardiovascular risk, Cardiovascular remodelling, Fetal echocardiography, Fetal programming.

This article is protected by copyright. All rights reserved. 


\section{MANUSCRIPT}

\section{INTRODUCTION}

Cardiovascular disease remains the main cause of mortality in developed countries, with research demonstrating a long subclinical phase that may include decades before the presence of clinical symptoms ${ }^{1,2}$. Large epidemiological studies associating low birth weight with myocardial infarction and cardiovascular related events in adulthood were first reported almost 3 decades ago, introducing the concept of fetal programming of cardiovascular disease $^{3}$. Recently, fetal cardiovascular adaptation to intrauterine growth restriction (IUGR) has been demonstrated to lead to primary cardiac changes, in the form of subclinical cardiovascular dysfunction and remodelling ${ }^{4-7}$.

The heart is a key organ in the fetal adaptation to hypoxia and undernutrition due to placental insufficiency in IUGR. Recent studies on fetal cardiac function have demonstrated that IUGR results in subclinical cardiovascular dysfunction in utero that can be demonstrated by various echocardiographic parameters, such as pulsed/tissue Doppler imaging or M-mode ${ }^{4,5,8-10}$. In addition, placental insufficiency has been associated to aortic restriction, higher resting heart rate, hypertension, increased vascular wall thickness and cardiac remodelling in IUGR newborns, infants, children and young adults ${ }^{6,11-14}$. However, the transition from fetal to postnatal cardiovascular remodelling has not been evaluated longitudinally. Consequently, the extent to which postnatal changes are a consequence of fetal cardiovascular remodelling or are influenced by other neonatal or early life events remains uncertain.

\section{METHODS}

Study population. The study design was a prospective cohort study including cases with IUGR and controls identified in fetal life and followed into infancy. The source population comprised all pregnancies beyond 34 weeks' gestation from April 2010 to September 2012 
from Hospital Clínic in Barcelona, Spain. Pregnancies with structural/chromosomal anomalies, twins, evidence of fetal infection or conception by assisted reproduction technologies were excluded from the study. IUGR was defined as an estimated fetal weight (EFW) and confirmed birth weight below the $10^{\text {th }}$ centile according to local reference curves $^{15}$. The reference cohort of fetuses with normal EFW and birth weight were randomly sampled from pregnancies at our institution and paired with IUGR cases by gestational age at fetal scan. The study protocol was approved by the Hospital Clínic Ethics Committee, and written parental consent was obtained for all study participants.

Baseline characteristics and pregnancy outcome. Upon fetal examination maternal characteristics such as age, height, weight, body mass index, smoking during pregnancy and parity were recorded. Gestational age at fetal scan was calculated based on the crown-rump length obtained at first trimester screening ${ }^{16}$. All women underwent ultrasonographic examination using a Siemens Sonoline Antares machine (Siemens Medical Systems, Malvern, PA, USA) which included EFW and standard obstetric Doppler evaluation comprising measurement of uterine arteries' (UtA) mean pulsatility index (PI), umbilical artery PI, middle cerebral artery PI and ductus venosus PI and cerebroplacental ratio (CPR) according to previously published methodology ${ }^{17-20}$. Doppler parameters were normalized into $\mathrm{Z}$-scores according to previously published reference values ${ }^{17-20}$. EFW was calculated according to the method of Hadlock et $\mathrm{al}^{21}$ and EFW centile was calculated using local reference curves ${ }^{15}$.

Upon delivery, presence of pregnancy complications, prenatal glucocorticoid exposure, gestational age at birth, mode of delivery, birth weight, birth weight centile, Apgar scores, and days in the neonatal intensive care unit were recorded. Birth weight centile was calculated using local reference curves ${ }^{15}$. 
Echocardiographic assessment. Fetal echocardiography was performed initially to assess structural heart integrity using a Siemens Sonoline Antares machine (Siemens Medical Systems, Malvern, PA, USA). Cardiovascular evaluation was performed using a curved-array 2-6 $\mathrm{MHz}$ transducer, with the exception of tissue Doppler measurements that required a phased-array 2-10 MHz transducer. Infant echocardiography was performed using Vivid Q (General Electric Healthcare, Horten, Norway). We calculated the estimated date of delivery based on $1^{\text {st }}$ trimester crown-rump length (i.e. 40 weeks gestation) and scheduled follow-up at 6 months from this date (6 months of corrected age). A complete two-dimensional M-mode and Doppler echocardiographic examination, with a 10S-RS phased-array $4.5-11.5 \mathrm{MHz}$ transducer, was performed to verify structural heart integrity, with morphometric and functional data also recorded. A complete description of the prenatal and postnatal evaluation may be found in the Supplementary Methods section; the following measurements were performed at both points in time:

Cardiac morphometry included left atrial area, ventricular sphericity index and interventricular septum thickness.

Systolic function evaluation included heart rate, ejection fraction (EF), stroke volumes (SV), cardiac outputs (CO), mitral/tricuspid annular-plane systolic excursion (MAPSE/TAPSE) and systolic annular peak velocities (S').

Diastolic function was evaluated by left isovolumetric relaxation time (IRT), peak early/late transvalvular filling velocities (E/A) ratio, E deceleration time, A duration time and early diastolic (E') and late diastolic (A') annular peak velocities.

Infant vascular evaluation. Vascular assessment included blood pressure measurement and aortic intima-media thickness (aIMT) measurement by ultrasound using Vivid Q (General Electric Healthcare, Horten, Norway) and a 12L-RS linear-array 6.0-13.0 MHz transducer. A controlled environment contributed to the achievement of all infant measurements.

This article is protected by copyright. All rights reserved. 
Systolic and diastolic blood pressure was obtained from the brachial artery using a validated ambulatory automated Omron 5 Series device. An appropriate cuff size covering $40 \%$ of the arm circumference was used to ensure accurate measurements ${ }^{22}$. Each infant's blood pressure was evaluated twice during quiescence and the average was determined. Measurement of aIMT in the upper abdomen involved obtaining longitudinal clips of the far wall of the proximal abdominal aorta in the upper abdomen with a 12L-RS linear-array 6.013.0 $\mathrm{MHz}$ transducer ${ }^{23,24}$. aIMT measurements were performed offline according to a standardized protocol based on a trace method with the assistance of a computerized program (GE EchoPAC PC 108.1.x, General Electric Healthcare $)^{25,26 .}$

Statistical analysis. Data was analyzed using the IBM SPSS Statistics 21 statistical package. Comparisons between the study and control groups were done with Student's t test, and are presented as mean \pm standard deviation (SD) or percentage (\%) where appropriate. P-values below 0.05 were considered statistically significant. Fetal parameters were adjusted with linear regression for gender, gestational age at delivery and preeclampsia. Infant parameters were adjusted by gender, gestational age at delivery, prenatal glucocorticoid exposure, cesarean section, neonatal intensive care unit hospitalization and body surface area by linear regression analysis.

\section{RESULTS}

In total, 95 late-IUGR fetuses were included for the study in prenatal life; 3 cases were excluded prenatally upon diagnosis of chromosomal and other structural abnormalities. From the remaining 92 patients, 10 were lost on follow-up after delivery and 2 were excluded because of postnatal diagnosis of pulmonary stenosis, leaving us with 80 IUGR cases, paired with 80 controls also recruited in prenatal life.

This article is protected by copyright. All rights reserved. 
Baseline and perinatal characteristics of the study groups. Baseline, perinatal and infant anthropometric characteristics of the study groups are shown in Table 1. Maternal characteristics were similar between groups. Gestational age at fetal scan showed no difference, but as expected, prenatal Doppler parameters and pregnancy outcomes were significantly worse in the IUGR group. $21.4 \%$ of the IUGR had abnormal UtA and $10.4 \%$ abnormal umbilical artery Doppler. 9.1\% showed brain vasodilation with abnormal middle cerebral artery PI and 28.6\% had abnormal CPR. Anthropometric data for the 6 month-old infants showed IUGR infants with significantly lower height, weight, body mass index and body surface area as compared to controls, with no significant difference in age at assessment or gender.

Fetal and postnatal echocardiography. Results of both fetal and infant echocardiography in the study groups are shown in Table 2 and Figure 1. Cardiac morphometric findings were concordant between the fetal and infant evaluation, showing larger atrial areas in the IUGR group as compared to controls, decreased left sphericity index and thicker septal wall. Global systolic function parameters such as heart rate, EF, SV and CO showed little or no differences between groups at both points in time. Longitudinal motion parameters MAPSE, TAPSE and S' peak velocities were all significantly decreased in the IUGR group with respect to controls both pre- and postnatally. For diastolic function parameters, the IRT was increased in the IUGR group, while tissue Doppler velocities E' and A' were significantly decreased in fetuses and infants alike. E/A ratios showed a significant increase in the IUGR fetus, but this did not persist into infancy. On the contrary, both E deceleration and A duration times showed a non-significant trend towards higher values in the IUGR fetus, that became significant in the IUGR infants when compared to controls.

Prenatal classification of IUGR severity and cardiac function. We performed a comparison of echocardiographic parameters between different stages of severity within the 
IUGR group, in accordance to the classification published recently ${ }^{27}$. We subdivided the group into small-for-gestational-age (SGA), defined by EFW between the $3^{\text {rd }}$ and $9^{\text {th }}$ centile together with normal CPR and UtA Doppler; and IUGR defined by EFW $<3^{\text {rd }}$ centile or EFW $<10^{\text {th }}$ centile together with $\mathrm{CPR}<5^{\text {th }}$ centile and/or mean UtA PI $>95^{\text {th }}$ centile. Fetal echocardiographic results are displayed in Table 3. Both SGA and IUGR presented changes in cardiac shape, with larger and more globular hearts, and signs of cardiac dysfunction, however there were no significant differences in cardiac function between these groups.

Infant vascular assessment. Vascular data (Table 4) showed systolic, diastolic and mean blood pressures significantly higher in the IUGR group. Both mean and maximum aIMT measurements were significantly increased in IUGR infants when compared to controls, and these differences were maintained when adjusted by linear regression to perinatal confounding factors.

\section{DISCUSSION}

This study confirms the presence of cardiovascular remodelling and dysfunction in IUGR and demonstrates that a pattern of change is already present in fetal life and remains essentially the same at 6 months of age. Our findings support the notion that primary cardiovascular remodelling starts in fetal life and is a main determinant of postnatal cardiac and vascular changes observed in IUGR children. Likewise, the study supports cardiovascular remodelling can be evidenced by functional echocardiography in utero and early infancy.

To our knowledge, this study is the first to perform an extensive functional echocardiography pre- and postnatally in the same IUGR subjects. The data supports previous studies demonstrating cardiac and vascular remodelling in IUGR children, characterized by more globular hearts, maintained EF and $\mathrm{CO}$ with subclinical systolic dysfunction and subclinical diastolic dysfunction, along with increased blood pressure and aIMT ${ }^{6,7,23,24,28}$. Our study

This article is protected by copyright. All rights reserved. 
also concurs with previous studies that have reported some of these findings prenatally, such as longitudinal dysfunction in IUGR fetuses ${ }^{4,5,9,28}$, or diastolic dysfunction by prolonged IRT $^{28,29}$. Fetal cardiac output demonstrated a right-sided dominance, with higher values in IUGR fetuses, in line with previous data demonstrating a shift towards higher volume load in the right ventricle, augmented during the last weeks of pregnancy and in presence of IUGR ${ }^{30}$. We also observed changes in $\mathrm{CO}$, from prenatal to postnatal circulation, consistent with previous reports that suggest a change in RV to LV cardiac output ratio ${ }^{31}$, demonstrating left ventricle dominance in infancy, as expected. Our data shows that most of the aforementioned parameters present significant differences between groups at both evaluations, supporting the fact that there exists primary fetal cardiovascular programming, which persists into infancy. In this study we also found cardiac morphometric changes not previously reported in fetuses with IUGR ${ }^{32,33}$. A more globular shape, dilated atria and thicker myocardial walls have been associated to pressure changes and volume overload to the fetal heart, due to the chronic state of hypoxia and elevated placental resistances ${ }^{34,35}$. Pressure changes may lead to hypertrophy of the ventricular walls and changes in the local radius of curvature of the heart (creating a more spherical cavity) in order to compensate ${ }^{36}$. Previous studies have also demonstrated that IUGR children, adolescents and adults have higher blood pressures and markers for cardiovascular risk, such as increased carotid and aortic $\mathrm{IMT}^{24}$ or changes in vessel diameter and heart rate $e^{6,12,37}$. In our study we confirm a significant difference in blood pressure and aIMT amongst our study groups in infancy, thus demonstrating that these changes can be characterized at an early stage in life. Some studies in animal models have found dilated-like cardiomyopathy in severe early IUGR, with lower ventricular mass and thinner myocardial walls $^{38,39}$, which may be explained that the variability in timing of onset (early or late in gestation) and severity of the placental disease among the studies and different animal models. The majority of our population was comprised of near term (late) IUGR, which may 
not be comparable to the described changes in very preterm (early) IUGR, subjected to extreme hypoxia early in gestation. Furthermore, our data agrees with other studies that evidence the presence of subtle cardiac dysfunction in late-onset IUGR, regardless of the presence of Doppler abnormalities that are predictors of poorer perinatal outcome ${ }^{40}$. This reinforces the idea that these parameters do not discriminate fetal cardiovascular programming, and all IUGR infants are, potentially, at risk for cardiovascular disease and may benefit from postnatal surveillance.

Strengths and limitations. Among the strengths of our study is the longitudinal workup from fetal life to infancy, which allowed a prospective evaluation of structural and functional echocardiographic parameters. Results were adjusted by all parameters considered relevant or potential perinatal confounders. Examination at 6 months of age was chosen as a reasonable point in time to avoid effects of neonatal cardiovascular transition to postnatal life, although we recognize that blood pressure measurement at 6 months of age is challenging and presents high variability, in spite of strict protocols ${ }^{22}$. We also acknowledge there might be differences in measurements when using different equipments pre- and postnatally ${ }^{41}$. Likewise, we admit that cardiac output is a very variable parameter with limitations for its acquisition in fetal and postnatal life, although low coefficients of variation and good intra-class correlations have been reported in spite of the lack of concurrent electrical timing of events in the fetus ${ }^{30,42}$. This data provides strong evidence to support that, regardless of the logical existence of postnatal environmental modulators, primary cardiovascular remodelling occurring in utero is a main determinant of cardiovascular dysfunction in children with IUGR. We also acknowledge that although this study provides evidence of cardiac remodelling at 6 months of age, a direct association with cardiovascular outcomes or persistence of these findings in the long-term remains to be seen and further follow-up of this cohort is required.

This article is protected by copyright. All rights reserved. 
Overall, our study provides more evidence supporting the notion that fetal primary cardiovascular remodelling exists in IUGR and that this group should be considered at risk for cardiovascular disease later in life. The diagnosis of IUGR is established in about $5-10 \%$ of pregnancies thus, the findings of this study would affect thousands of children per year. Hypertension in the child has been associated with substantial long-term health risks ${ }^{22}$, whereas aIMT measurement allows detection of increased cardiovascular risk, as an indicator of arterial remodelling in children ${ }^{23,24,43}$. Our study supports earlier screening in this population so that they may benefit of early interventions, such as lack of exposure to other risk factors, surveillance of catch-up growth and promotion of breastfeeding, exercise and physical activity ${ }^{22}$. Recent studies have also demonstrated the benefit of a high intake of dietary long-chain $\omega-3$ fatty acids in reducing blood pressure, preventing progression of subclinical atherosclerosis in children born with low birth weight ${ }^{43}$ or the benefit of a Mediterranean diet in reduction of cardiovascular risk ${ }^{44,45}$. These all are interventions that could be applied to this population to reduce the probability of cardiovascular disease later in life.

\section{CONCLUSIONS}

Primary cardiovascular changes in IUGR are present in the fetus and persist at 6 months of age. The data supports the ability to demonstrate changes early in life, which could be used to monitor early interventions and diminish cardiovascular risk in this population.

This article is protected by copyright. All rights reserved. 


\section{FUNDING}

This work was supported by grants from Instituto de Salud Carlos III [grant numbers PI11/00051, PI12/00801, PI11/01709], from the Ministerio de Economía y Competitividad [grant number SAF2012-37196], cofinanced by the Fondo Europeo de Desarrollo Regional de la Unión Europea "Una manera de hacer Europa”, Fundación Mutua Madrileña, Fundació Agrupació Premi Àmbit de la Infància (Spain) and Cerebra Foundation for the Brain Injured Child (Carmarthen, Wales, UK). B.V.A. was supported by Programa de Ayudas Postdoctorales FI Agaur (2013FI_B 00667). M.C.L. and B.V.A. wish to express their gratitude to the Mexican National Council of Science and Technology (CONACyT, Mexico City, Mexico) for partially supporting their predoctoral stays at Hospital Clínic, Barcelona, Spain.

Conflict of interest: none declared. 


\section{REFERENCES}

1. Hansson GK. Inflammation, atherosclerosis, and coronary artery disease. $N$ Engl $J$ Med 2005; 352: 1685-1695.

2. Murray CJ and Lopez AD. Global mortality, disability, and the contribution of risk factors: Global Burden of Disease Study. Lancet 1997; 349: 1436-1442.

3. Barker DJ, Osmond C, Golding J, Kuh D and Wadsworth ME. Growth in utero, blood pressure in childhood and adult life, and mortality from cardiovascular disease. BMJ 1989; 298: 564-567.

4. Comas M, Crispi F, Cruz-Martinez R, Figueras F and Gratacos E. Tissue Doppler echocardiographic markers of cardiac dysfunction in small-for-gestational age fetuses. Am $J$ Obstet Gynecol 2011; 205: 57 e51-56.

5. Comas M, Crispi F, Cruz-Martinez R, Martinez JM, Figueras F and Gratacos E. Usefulness of myocardial tissue Doppler vs conventional echocardiography in the evaluation of cardiac dysfunction in early-onset intrauterine growth restriction. Am J Obstet Gynecol 2010; 203: 45 e41-47.

6. Crispi F, Bijnens B, Figueras F, Bartrons J, Eixarch E, Le Noble F, Ahmed A and Gratacos E. Fetal growth restriction results in remodeled and less efficient hearts in children. Circulation 2010; 121: 2427-2436.

7. Crispi F, Figueras F, Cruz-Lemini M, Bartrons J, Bijnens B and Gratacos E. Cardiovascular programming in children born small for gestational age and relationship with prenatal signs of severity. Am J Obstet Gynecol 2012; 207: 121 e121-129.

8. Crispi F, Hernandez-Andrade E, Pelsers MM, Plasencia W, Benavides-Serralde JA, Eixarch E, Le Noble F, Ahmed A, Glatz JF, Nicolaides KH and Gratacos E. Cardiac dysfunction and cell damage across clinical stages of severity in growth-restricted fetuses. Am J Obstet Gynecol 2008; 199: 254 e251-258.

This article is protected by copyright. All rights reserved. 
9. Cruz-Lemini M, Crispi F, Valenzuela-Alcaraz B, Figueras F, Sitges M, Gomez O, Bijnens B and Gratacos E. Value of annular M-mode displacement versus tissue Doppler velocities to assess cardiac function in intrauterine growth restriction. Ultrasound Obstet Gynecol 2013.

10. Demicheva E and Crispi F. Long-Term Follow-Up of Intrauterine Growth Restriction: Cardiovascular Disorders. Fetal Diagn Ther 2013.

11. Bjarnegard N, Morsing E, Cinthio M, Lanne $\mathrm{T}$ and Brodszki J. Cardiovascular function in adulthood following intrauterine growth restriction with abnormal fetal blood flow. Ultrasound Obstet Gynecol 2013; 41: 177-184.

12. Brodszki J, Lanne T, Marsal K and Ley D. Impaired vascular growth in late adolescence after intrauterine growth restriction. Circulation 2005; 111: 2623-2628.

13. Turan S, Turan OM, Salim M, Berg C, Gembruch U, Harman CR and Baschat AA. Cardiovascular transition to extrauterine life in growth-restricted neonates: relationship with prenatal Doppler findings. Fetal Diagn Ther 2013; 33: 103-109.

14. Zanardo V, Visentin S, Trevisanuto D, Bertin M, Cavallin F and Cosmi E. Fetal aortic wall thickness: a marker of hypertension in IUGR children? Hypertens Res 2013; 36: 440443.

15. Figueras F, Meler E, Iraola A, Eixarch E, Coll O, Figueras J, Francis A, Gratacos E and Gardosi J. Customized birthweight standards for a Spanish population. Eur J Obstet Gynecol Reprod Biol 2008; 136: 20-24.

16. Robinson HP, Sweet EM and Adam AH. The accuracy of radiological estimates of gestational age using early fetal crown-rump length measurements by ultrasound as a basis for comparison. Br J Obstet Gynaecol 1979; 86: 525-528.

17. Arduini D and Rizzo G. Normal values of Pulsatility Index from fetal vessels: a crosssectional study on 1556 healthy fetuses. J Perinat Med 1990; 18: 165-172.

This article is protected by copyright. All rights reserved. 
18. Gomez O, Figueras F, Fernandez S, Bennasar M, Martinez JM, Puerto B and Gratacos E. Reference ranges for uterine artery mean pulsatility index at 11-41 weeks of gestation. Ultrasound Obstet Gynecol 2008; 32: 128-132.

19. Hecher K, Campbell S, Snijders R and Nicolaides K. Reference ranges for fetal venous and atrioventricular blood flow parameters. Ultrasound Obstet Gynecol 1994; 4: 381390.

20. Baschat AA and Gembruch U. The cerebroplacental Doppler ratio revisited. Ultrasound Obstet Gynecol 2003; 21: 124-127.

21. Hadlock FP, Harrist RB, Shah YP, King DE, Park SK and Sharman RS. Estimating fetal age using multiple parameters: a prospective evaluation in a racially mixed population. Am J Obstet Gynecol 1987; 156: 955-957.

22. Adolescents NHBPEPWGoHBPiCa. The fourth report on the diagnosis, evaluation, and treatment of high blood pressure in children and adolescents. Pediatrics 2004; 114: 555576.

23. Dulac Y, Tauber M and Jouret B. Aortic or carotid intima-media thickness to evaluate children born small for gestational age? Horm Res Paediatr 2012; 77: 340.

24. Skilton MR, Evans N, Griffiths KA, Harmer JA and Celermajer DS. Aortic wall thickness in newborns with intrauterine growth restriction. Lancet 2005; 365: 1484-1486.

25. Stein JH, Korcarz CE, Hurst RT, Lonn E, Kendall CB, Mohler ER, Najjar SS, Rembold CM and Post WS. Use of carotid ultrasound to identify subclinical vascular disease and evaluate cardiovascular disease risk: a consensus statement from the American Society of Echocardiography Carotid Intima-Media Thickness Task Force. Endorsed by the Society for Vascular Medicine. J Am Soc Echocardiogr 2008; 21: 93-111; quiz 189-190.

26. Stergiotou I, Crispi F, Valenzuela-Alcaraz B, Cruz-Lemini M, Bijnens B and Gratacos E. Aortic And Carotid Wall Thickness In Term Small-For-Gestational Age 
Newborns And Relationship With Prenatal Signs Of Severity. Ultrasound Obstet Gynecol 2013.

27. Figueras F and Gratacos E. Update on the diagnosis and classification of fetal growth restriction and proposal of a stage-based management protocol. Fetal Diagn Ther 2014; 36: $86-98$.

28. Cruz-Lemini M, Crispi F, Valenzuela-Alcaraz B, Figueras F, Gomez O, Sitges M, Bijnens B and Gratacos E. A fetal cardiovascular score to predict infant hypertension and arterial remodeling in intrauterine growth restriction. Am J Obstet Gynecol 2014; 210: 552 e551-552 e522.

29. Hernandez-Andrade E, Benavides-Serralde JA, Cruz-Martinez R, Welsh A and Mancilla-Ramirez J. Evaluation of conventional Doppler fetal cardiac function parameters: E/A ratios, outflow tracts, and myocardial performance index. Fetal Diagn Ther 2012; 32: 22-29.

30. Kiserud T, Ebbing C, Kessler J and Rasmussen S. Fetal cardiac output, distribution to the placenta and impact of placental compromise. Ultrasound Obstet Gynecol 2006; 28: 126136.

31. Patey O, Thilaganathan B and Carvalho JS. OP26.10: Perinatal changes in cardiac function: improvement from fetus to neonate. Ultrasound Obstet Gynecol 2014; 44: 148.

32. Munoz-Abellana B, Hernandez-Andrade E, Figueroa-Diesel H, Ferrer Q, AcostaRojas R, Cabero L and Gratacos E. Hypertrophic cardiomyopathy-like changes in monochorionic twin pregnancies with selective intrauterine growth restriction and intermittent absent/reversed end-diastolic flow in the umbilical artery. Ultrasound Obstet Gynecol 2007; 30: 977-982.

33. Valenzuela-Alcaraz B, Crispi F, Bijnens B, Cruz-Lemini M, Creus M, Sitges M, Bartrons J, Civico S, Balasch J and Gratacos E. Assisted reproductive technologies are 
associated with cardiovascular remodeling in utero that persists postnatally. Circulation 2013; 128: 1442-1450.

34. Gardiner H, Brodszki J and Marsal K. Ventriculovascular physiology of the growthrestricted fetus. Ultrasound Obstet Gynecol 2001; 18: 47-53.

35. Verburg BO, Jaddoe VW, Wladimiroff JW, Hofman A, Witteman JC and Steegers EA. Fetal hemodynamic adaptive changes related to intrauterine growth: the Generation $\mathrm{R}$ Study. Circulation 2008; 117: 649-659.

36. Baltabaeva A, Marciniak M, Bijnens B, Moggridge J, He FJ, Antonios TF, MacGregor GA and Sutherland GR. Regional left ventricular deformation and geometry analysis provides insights in myocardial remodelling in mild to moderate hypertension. Eur $J$ Echocardiogr 2008; 9: 501-508.

37. Morsing E, Liuba P, Fellman V, Marsal K and Brodszki J. Cardiovascular function in children born very preterm after intrauterine growth restriction with severely abnormal umbilical artery blood flow. Eur J Prev Cardiol 2013.

38. Ream M, Ray AM, Chandra R and Chikaraishi DM. Early fetal hypoxia leads to growth restriction and myocardial thinning. Am J Physiol Regul Integr Comp Physiol 2008; 295: R583-595.

39. Tintu A, Rouwet E, Verlohren S, Brinkmann J, Ahmad S, Crispi F, van Bilsen M, Carmeliet P, Staff AC, Tjwa M, Cetin I, Gratacos E, Hernandez-Andrade E, Hofstra L, Jacobs M, Lamers WH, Morano I, Safak E, Ahmed A and le Noble F. Hypoxia induces dilated cardiomyopathy in the chick embryo: mechanism, intervention, and long-term consequences. PLoS One 2009; 4: e5155.

40. Perez-Cruz M, Cruz-Lemini M, Fernandez MT, Parra JA, Casas JB, Gomez-Roig $\mathrm{MD}$, Crispi $\mathrm{F}$ and Gratacos E. Fetal cardiac function in late-onset "intrauterine growth restriction" versus "small-for-gestational age" as defined by estimated fetal weight, cerebro- 
placental ratio and uterine artery Doppler. Ultrasound Obstet Gynecol 2015. doi: 10.1002/uog.14930. [Epub ahead of print]

41. Denes M, Farkas K, Erdei T and Lengyel M. Comparison of tissue Doppler velocities obtained by different types of echocardiography systems: are they compatible? Echocardiography 2010; 27: 230-235.

42. Gardiner HM. Foetal cardiac function: assessing new technologies. Cardiology in the young 2014; 24 Suppl 2: 26-35.

43. Skilton MR, Ayer JG, Harmer JA, Webb K, Leeder SR, Marks GB and Celermajer DS. Impaired fetal growth and arterial wall thickening: a randomized trial of omega-3 supplementation. Pediatrics 2012; 129: e698-703.

44. Estruch R, Ros E, Salas-Salvado J, Covas MI, Corella D, Aros F, Gomez-Gracia E, Ruiz-Gutierrez V, Fiol M, Lapetra J, Lamuela-Raventos RM, Serra-Majem L, Pinto X, Basora J, Munoz MA, Sorli JV, Martinez JA and Martinez-Gonzalez MA. Primary prevention of cardiovascular disease with a Mediterranean diet. $N$ Engl $J$ Med 2013; 368: 1279-1290.

45. Rees K, Dyakova M, Wilson N, Ward K, Thorogood M and Brunner E. Dietary advice for reducing cardiovascular risk. Cochrane Database Syst Rev 2013; 12: CD002128.

This article is protected by copyright. All rights reserved. 
Figure 1. Echocardiographic images of pre- and postnatal echocardiography in a control and IUGR patient.

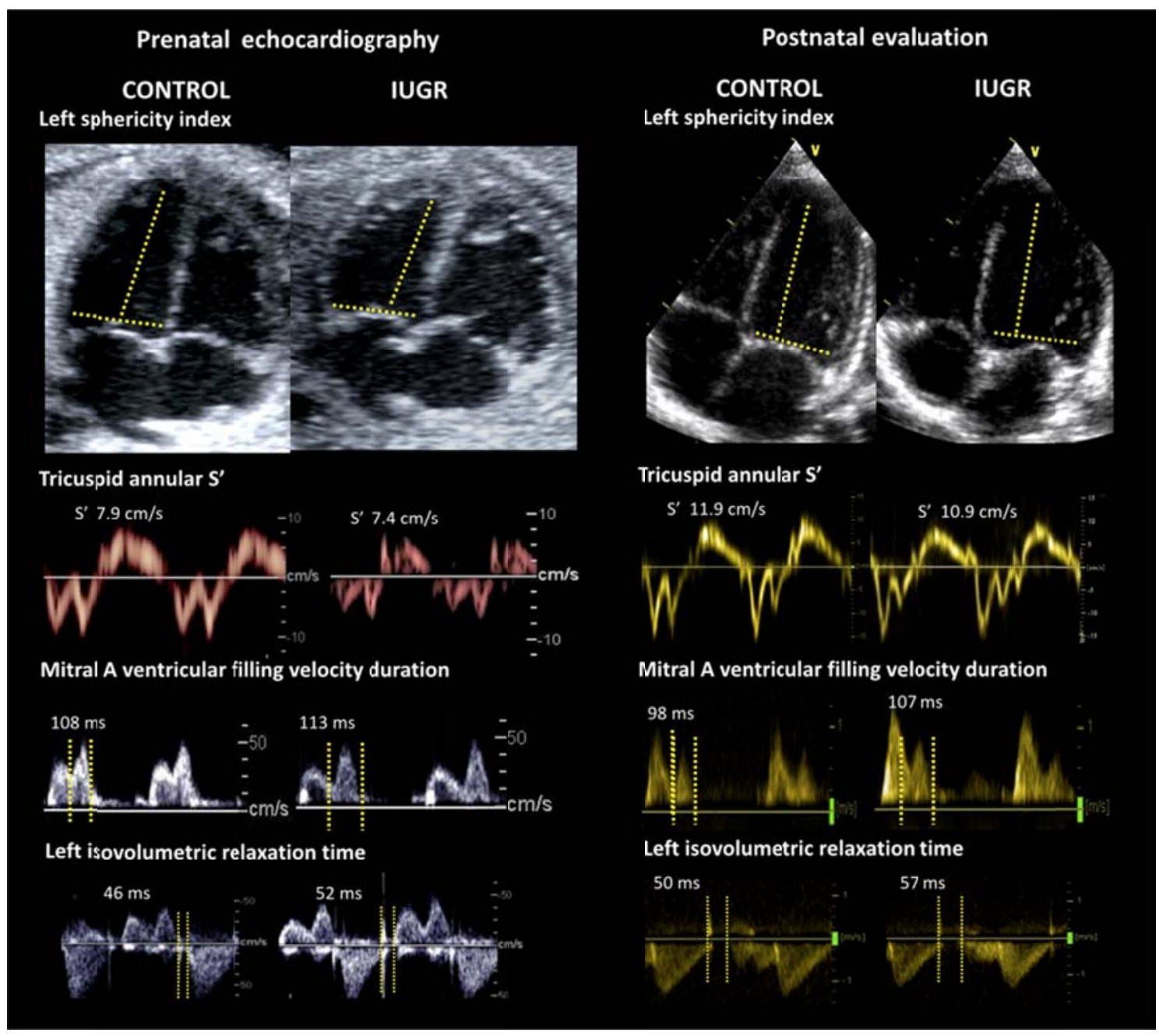

From top to bottom: a) two-dimensional apical 4-chamber views at end-diastole illustrating left ventricule sphericity index measurement, b) tricuspid systolic $\left(\mathrm{S}^{\prime}\right)$ annular myocardial peak velocity, c) mitral A transvalvular filling velocity duration and d) left isovolumetric relaxation time.

This article is protected by copyright. All rights reserved. 
Table 1. Baseline characteristics of the study groups.

\begin{tabular}{|c|c|c|c|}
\hline & $\begin{array}{c}\text { Controls } \\
(n=80)\end{array}$ & $\begin{array}{c}\text { IUGR } \\
(n=80)\end{array}$ & p-value \\
\hline \multicolumn{4}{|c|}{ Maternal characteristics } \\
\hline$\overline{\text { Age (years) }}$ & $33 \pm 5$ & $33 \pm 6$ & 0.289 \\
\hline Height (cm) & $164 \pm 7$ & $161 \pm 6$ & 0.388 \\
\hline Weight $(\mathrm{Kg})$ & $60.6 \pm 11.3$ & $58.8 \pm 13.1$ & 0.353 \\
\hline Body mass index $\left(\mathrm{Kg} / \mathrm{m}^{2}\right)$ & $22.4 \pm 3.8$ & $22.6 \pm 4.6$ & 0.692 \\
\hline Smoking $(\%)$ & 21 & 23 & 0.685 \\
\hline Nulliparity (\%) & 57 & 68 & 0.073 \\
\hline \multicolumn{4}{|c|}{ Fetoplacental ultrasound } \\
\hline Gestational age at scan (weeks) & $37.9 \pm 3.44$ & $37.1 \pm 2.33$ & 0.078 \\
\hline Estimated fetal weight (grams) & $2149 \pm 456$ & $1919 \pm 812$ & 0.028 \\
\hline Estimated fetal weight centile & $52 \pm 24$ & $3 \pm 3$ & $<0.001$ \\
\hline Mean uterine artery PI & $0.68 \pm 0.18$ & $0.75 \pm 0.26$ & 0.022 \\
\hline Umbilical artery PI & $1.04 \pm 0.20$ & $1.11 \pm 0.34$ & 0.004 \\
\hline Middle cerebral artery PI & $1.99 \pm 0.34$ & $1.51 \pm 0.42$ & $<0.001$ \\
\hline Cerebroplacental ratio & $1.99 \pm 0.50$ & $1.52 \pm 0.60$ & $<0.001$ \\
\hline Ductus venosus PI & $0.52 \pm 0.16$ & $0.51 \pm 0.17$ & 0.089 \\
\hline \multicolumn{4}{|c|}{ Pregnancy outcomes } \\
\hline Prenatal glucocorticoid exposure (\%) & 0 & 6 & 0.020 \\
\hline Preeclampsia $(\%)$ & 1 & 4 & 0.287 \\
\hline Gestational age at delivery (weeks) & $40.2 \pm 1.1$ & $38.6 \pm 1.5$ & $<0.001$ \\
\hline Delivery $>37$ weeks $(\%)$ & 100 & 85 & 0.003 \\
\hline Cesarean section $(\%)$ & 15 & 29 & 0.022 \\
\hline Birth weight $(\mathrm{g})$ & $3390 \pm 368$ & $2394 \pm 400$ & $<0.001$ \\
\hline Birth weight centile & $50 \pm 25$ & $3 \pm 4$ & $<0.001$ \\
\hline 5-minute Apgar score < $7(\%)$ & 0 & 5 & 0.035 \\
\hline Days in neonatal intensive care unit & $0 \pm 1$ & $3 \pm 8$ & $<0.001$ \\
\hline \multicolumn{4}{|c|}{$\begin{array}{ll}\text { Infant anthropometric data } \\
\end{array}$} \\
\hline Corrected age at evaluation (months) & $6.5 \pm 0.5$ & $6.4 \pm 0.5$ & 0.303 \\
\hline Male gender $(\%)$ & 44 & 55 & 0.086 \\
\hline Height $(\mathrm{cm})$ & $67.7 \pm 2.7$ & $65.1 \pm 2.4$ & $<0.001$ \\
\hline Weight (grams) & $7713 \pm 725$ & $6907 \pm 793$ & $<0.001$ \\
\hline Body mass index $\left(\mathrm{Kg} / \mathrm{m}^{2}\right)$ & $16.9 \pm 1.9$ & $16.3 \pm 1.7$ & 0.048 \\
\hline Body surface area $\left(\mathrm{m}^{2}\right)$ & $0.36 \pm 0.02$ & $0.34 \pm 0.02$ & $<0.001$ \\
\hline
\end{tabular}

This article is protected by copyright. All rights reserved. 
able 2. Echocardiographic evaluation of the study populations at fetal life and 6 months of age.

\begin{tabular}{|c|c|c|c|c|c|c|}
\hline & \multicolumn{3}{|c|}{ Prenatal echocardiography } & \multicolumn{3}{|c|}{ Postnatal evaluation } \\
\hline & $\begin{array}{c}\text { Controls } \\
(\mathbf{n}=\mathbf{8 0})\end{array}$ & $\begin{array}{l}\text { IUGR } \\
(\mathbf{n}=\mathbf{8 0})\end{array}$ & p value* & $\begin{array}{c}\text { Controls } \\
(\mathbf{n}=\mathbf{8 0})\end{array}$ & $\begin{array}{l}\text { IUGR } \\
(\mathbf{n}=\mathbf{8 0})\end{array}$ & $p$ value $\dagger$ \\
\hline Age at echocardiography & $\begin{array}{c}37.9 \pm 3.44 \\
\text { weeks' gestation }\end{array}$ & $\begin{array}{c}37.1 \pm 2.33 \\
\text { weeks' gestation }\end{array}$ & 0.078 & $\begin{array}{c}6.5 \pm 0.5 \\
\text { months of age }\end{array}$ & $\begin{array}{c}6.4 \pm 0.5 \\
\text { months of age }\end{array}$ & 0.303 \\
\hline & Car & iac morphometry & & & & \\
\hline Left atrial area $\left(\mathrm{cm}^{2}\right)$ & $1.6 \pm 0.6$ & $1.9 \pm 0.6$ & 0.008 & $3.6 \pm 0.9$ & $3.8 \pm 0.7$ & 0.006 \\
\hline Left sphericity index & $2.06 \pm 0.37$ & $1.87 \pm 0.45$ & 0.022 & $1.92 \pm 0.28$ & $1.67 \pm 0.22$ & 0.007 \\
\hline Interventricular septum thickness (mm) & $2.7 \pm 0.6$ & $3.5 \pm 0.8$ & $<0.001$ & $3.9 \pm 0.7$ & $4.6 \pm 0.9$ & $<0.001$ \\
\hline & & stolic function & & & & \\
\hline Heart rate $(\mathrm{bpm})$ & $140 \pm 9$ & $138 \pm 12$ & 0.239 & $134 \pm 12$ & $132 \pm 12$ & 0.560 \\
\hline Left ejection fraction $(\%)$ & $70.9 \pm 8.7$ & $70.9 \pm 9.6$ & 0.692 & $65.7 \pm 8.1$ & $68.9 \pm 9.4$ & 0.083 \\
\hline Left stroke volume (mL) & $2.7 \pm 1.8$ & $3.3 \pm 1.5$ & 0.043 & $18.1 \pm 5.1$ & $20.1 \pm 6.9$ & 0.062 \\
\hline Right stroke volume (mL) & $3.8 \pm 1.8$ & $4.7 \pm 1.8$ & $<0.001$ & $14.3 \pm 3.7$ & $12.9 \pm 4.3$ & 0.081 \\
\hline Left cardiac output (L/min) & $0.4 \pm 0.2$ & $0.5 \pm 0.2$ & 0.265 & $2.4 \pm 0.6$ & $2.7 \pm 0.8$ & 0.089 \\
\hline Right cardiac output (L/min) & $0.5 \pm 0.2$ & $0.6 \pm 0.2$ & 0.001 & $1.9 \pm 0.5$ & $1.7 \pm 0.5$ & 0.021 \\
\hline MAPSE $(\mathrm{mm})$ & $5.3 \pm 1.2$ & $5.0 \pm 1.0$ & 0.913 & $10.9 \pm 1.9$ & $9.8 \pm 1.5$ & 0.001 \\
\hline TAPSE (mm) & $7.2 \pm 1.3$ & $6.8 \pm 1.2$ & 0.015 & $16.0 \pm 0.8$ & $14.2 \pm 0.8$ & $<0.001$ \\
\hline Mitral S' peak velocity $(\mathrm{cm} / \mathrm{s})$ & $7.2 \pm 1.3$ & $6.3 \pm 1.1$ & 0.003 & $7.9 \pm 1.7$ & $6.4 \pm 1.3$ & $<0.001$ \\
\hline Triduspid S' peak velocity $(\mathrm{cm} / \mathrm{s})$ & $7.9 \pm 1.4$ & $7.4 \pm 1.3$ & 0.045 & $11.9 \pm 2.1$ & $10.9 \pm 2.2$ & 0.039 \\
\hline & & astolic function & & & & \\
\hline Left isovolumetric relaxation time (ms) & $46 \pm 8$ & $52 \pm 8$ & $<0.001$ & $50 \pm 10$ & $57 \pm 10$ & 0.034 \\
\hline Mitral E/A ratio & $0.74 \pm 0.14$ & $0.80 \pm 0.15$ & 0.003 & $1.37 \pm 0.27$ & $1.35 \pm 0.28$ & 0.638 \\
\hline Mitral E deceleration time (ms) & $87 \pm 34$ & $97 \pm 28$ & 0.072 & $89 \pm 28$ & $97 \pm 25$ & 0.021 \\
\hline Mitral A duration time (ms) & $108 \pm 21$ & $113 \pm 20$ & 0.043 & $98 \pm 21$ & $107 \pm 23$ & 0.002 \\
\hline Mitral lateral annular E' peak velocity $(\mathrm{cm} / \mathrm{s})$ & $7.9 \pm 1.7$ & $6.9 \pm 1.4$ & 0.005 & $12.9 \pm 2.5$ & $11.1 \pm 2.0$ & 0.001 \\
\hline Mitral lateral annular A' peak velocity $(\mathrm{cm} / \mathrm{s})$ & $9.7 \pm 2.2$ & $7.6 \pm 1.4$ & $<0.001$ & $8.9 \pm 3.0$ & $6.9 \pm 1.9$ & $<0.001$ \\
\hline Tricuspid E/A ratio & $0.75 \pm 0.11$ & $0.80 \pm 0.18$ & 0.027 & $1.07 \pm 0.32$ & $0.99 \pm 0.23$ & 0.029 \\
\hline
\end{tabular}

This article is protected by copyright. All rights reserved. 


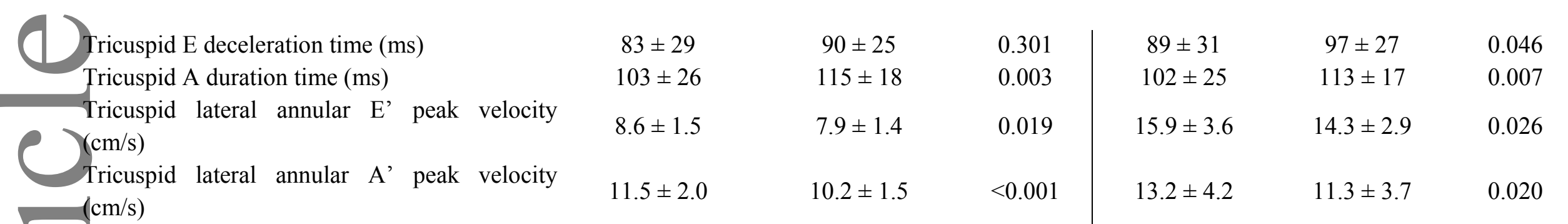

$(\mathrm{cm} / \mathrm{s})$

Data shown as mean \pm SD or percentage. IUGR, intrauterine growth restriction; MAPSE, mitral annular plane systolic excursion; S', systolic annular peak velocity; TAPSE, tricuspid annular plane systolic excursion; E, peak early transvalvular filling velocity; A, peak late transvalvular filling velocity; E', early diastole annular peak velocity; A', late diastole annular peak velocity.

*Fetal $\mathrm{p}$ values adjusted with linear regression for gender, gestational age at delivery and preeclampsia. $\dagger$ Infant $\mathrm{p}$ values adjusted with linear regression for gender, gestational age at delivery, prenatal glucocorticoid exposure, cesarean section, NICU hospitalization and body surface area.

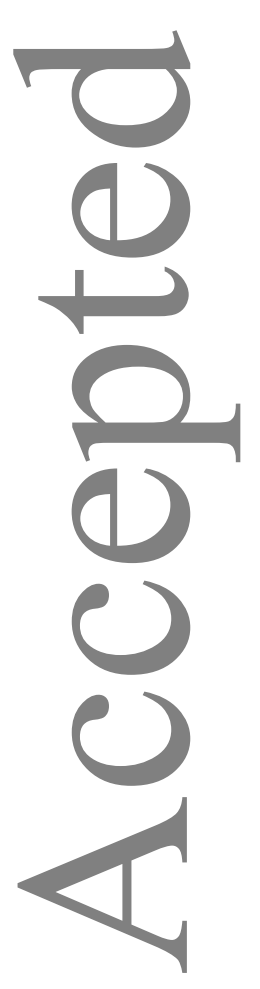

This article is protected by copyright. All rights reserved. 
Table 3. Fetal echocardiographic parameters at different stages of severity.

\begin{tabular}{lccc}
\hline & $\begin{array}{c}\text { SGA } \\
(\mathbf{n = 2 9 )}\end{array}$ & $\begin{array}{c}\text { IUGR } \\
(\mathbf{n = 5 1 )}\end{array}$ & p value \\
\hline Gestational age at scan (weeks) & $37.3 \pm 2.0$ & $36.7 \pm 2.6$ & 0.840 \\
Myocardial performance index & $0.55 \pm 0.08$ & $0.56 \pm 0.10$ & 0.625 \\
\hline \multicolumn{4}{c}{ Cardiac morphometry } \\
\hline Left sphericity index & $1.55 \pm 0.25$ & $1.67 \pm 0.35$ & 0.082 \\
Right sphericity index & $1.43 \pm 0.30$ & $1.42 \pm 0.22$ & 0.765 \\
Interventricular septum thickness (mm) & $3.4 \pm 0.8$ & $3.5 \pm 0.9$ & 0.708 \\
\hline & Systolic function & \\
\hline MAPSE (mm) & $5.2 \pm 1.1$ & $5.2 \pm 0.9$ & 0.970 \\
TAPSE (mm) & $6.8 \pm 1.5$ & $6.8 \pm 1.1$ & 0.825 \\
Mitral lateral S' peak velocity (cm/s) & $6.0 \pm 0.8$ & $6.2 \pm 1.2$ & 0.390 \\
Tricuspid S' peak velocity (cm/s) & $7.2 \pm 1.3$ & $7.5 \pm 1.3$ & 0.334 \\
\hline & Diastolic function & \\
\hline Left isovolumetric relaxation time (ms) & $52 \pm 8$ & $53 \pm 8$ & 0.678 \\
Mitral lateral E' peak velocity (cm/s) & $6.6 \pm 1.2$ & $7.1 \pm 1.5$ & 0.079 \\
Mitral lateral A' peak velocity (cm/s) & $7.4 \pm 1.5$ & $7.7 \pm 1.4$ & 0.354 \\
Tricuspid E' peak velocity (cm/s) & $7.9 \pm 1.4$ & $7.9 \pm 1.5$ & 0.978 \\
Tricuspid A' peak velocity (cm/s) & $9.9 \pm 1.6$ & $10.1 \pm 1.7$ & 0.604 \\
\hline
\end{tabular}

Data shown as mean \pm SD. SGA, small for gestational age; IUGR, intrauterine growth restriction, in accordance to classification proposed by Figueras F, Gratacós E. Fetal Diagn Ther 2014;36:86-98.

This article is protected by copyright. All rights reserved. 
Table 4. Vascular evaluation at 6 months of age.

\begin{tabular}{|c|c|c|c|}
\hline & $\begin{array}{c}\text { Controls } \\
(n=80)\end{array}$ & $\begin{array}{l}\text { IUGR } \\
(n=80)\end{array}$ & p-value \\
\hline \multicolumn{4}{|c|}{ Blood pressure } \\
\hline Systolic blood pressure (mmHg) & $76 \pm 10$ & $85 \pm 8$ & $<0.001$ \\
\hline Diastolic blood pressure $(\mathrm{mmHg})$ & $54 \pm 8$ & $62 \pm 7$ & $<0.001$ \\
\hline Mean blood pressure $(\mathrm{mmHg})$ & $61 \pm 8$ & $70 \pm 7$ & $<0.001$ \\
\hline \multicolumn{4}{|c|}{ aIMT } \\
\hline Mean aIMT (mm) & $0.487 \pm 0.066$ & $0.567 \pm 0.065$ & $<0.001$ \\
\hline Maximum aIMT (mm) & $0.566 \pm 0.070$ & $0.664 \pm 0.068$ & $<0.001$ \\
\hline
\end{tabular}

This article is protected by copyright. All rights reserved. 